\title{
Monetary Incentives and Mortgage Renegotiation Outcomes
}

Nika Lazaryan and Urvi Neelakantan

\section{INTRODUCTION}

The U.S. foreclosure crisis began in 2006, when over 700,000 properties received foreclosure filings (RealtyTrac Staff 2014). The number of filings increased every year until 2010, at which time they peaked at nearly 2.9 million. The inventory of mortgage foreclosures as a share of outstanding mortgages increased from around 1 percent in 2000 to 4.6 percent in $2010 .^{1}$ The historically unprecedented numbers prompted the U.S government to introduce several programs to reduce the number of foreclosures. ${ }^{2}$ Prominent among these programs was the Home Affordable Modification Program (HAMP), which was introduced in 2009. Its goal was to help homeowners avoid foreclosure by encouraging servicers to work with homeowners to modify the terms of their mortgage. HAMP offered servicers $\$ 1,000$ for each modification

- The idea for this paper germinated from a collaboration in 2010-12 with Community Development staff members at the Federal Reserve Bank of Richmond, whom we acknowledge with gratitude. This is a companion paper to Neelakantan et al. (2012), coauthored with Shannon McKay and Kim Zeuli, which assesses the predictions of the theoretical model presented in the current piece using survey data on homeowners who sought mortgage assistance. We thank Andreas Hornstein, Erica Paulos, Ned Prescott, Pierre-Daniel Sarte, Russell Wong, and seminar participants at the Federal Reserve Bank of Richmond for helpful comments. We are solely responsible for any errors. The views expressed in this paper are those of the authors and do not necessarily reflect the views of the Federal Reserve Bank of Richmond or the Federal Reserve System. Nika Lazaryan: Federal Reserve Bank of Richmond, P.O. Box 27622, Richmond, VA 23261, Nika.Lazaryan@rich.frb.org, Ph:804-697-5475. Urvi Neelakantan: Federal Reserve Bank of Richmond, P.O. Box 27622, Richmond, VA 23261, Urvi.Neelakantan@rich.frb.org, Ph:804-697-8146.

${ }^{1}$ Data from Mortgage Bankers Association via Haver Analytics.

2 See Gerardi and Li (2010) for a discussion of these programs. Prior to 2007, there were no federal programs addressing mortgage default (Hembre 2014). 
completed under the program (Making Home Affordable Program 2010). Additional incentives were offered to homeowners and servicers for up to three years for loans that remained in good standing. ${ }^{3}$ Compared to regular servicing fees of 20 to 50 basis points of the outstanding loan balance, these incentives were quite sizable. ${ }^{4}$

The goal of this paper is to examine the effect of incentives on mortgage renegotiation or modification (the terms are used interchangeably) outcomes. Specifically, we are interested in whether incentives offered to homeowners and servicers can indeed reduce foreclosures. ${ }^{5}$ To address this question, we use a simple model of renegotiation between the homeowner and lender. The model is a sequential-move game in which the homeowner moves first and decides whether to seek renegotiation. Next, the lender decides whether to modify the terms of the mortgage. The homeowner then decides whether to default. Homeowners who default are foreclosed upon. We compare the predictions of the model with no incentives to predictions of the model in which incentives are introduced.

Results show that, in the absence of incentives, lenders would renegotiate only with the subset of homeowners who would neither i) redefault despite receiving modified terms nor ii) self-cure without modified terms. (The ideas of "self-cure" and "redefault" are formalized in the model.) The renegotiation enables this subset of homeowners to avoid foreclosure. Once incentives are introduced, the subset of homeowners who receive renegotiated terms and avoid foreclosure is larger than the subset in the model without incentives. However, if incentive payments to the lender are sufficiently high, we find that lenders may also renegotiate with homeowners they know will subsequently redefault. To summarize, we find that incentives can indeed reduce the number of foreclosures, but there are scenarios in which some of the incentive payments are channeled to renegotations in which foreclosure is still the final outcome. Note that these are descriptive results; assessing the costs and benefits or the welfare implications of such outcomes, or of the particulars of the HAMP program, is beyond the scope of this paper. ${ }^{6}$

\footnotetext{
${ }^{3}$ The ongoing "pay-for-success" incentives included up to $\$ 1,000$ in yearly payments for three years after the modification for the borrowers who were current on their mortgage payments.

${ }^{4}$ Regular servicing fees on a mortgage with a $\$ 200,000$ balance are between $\$ 400$ and $\$ 1,000$ per year (Agarwal et al. 2012).

${ }^{5}$ We use the term "servicer" and "lender" interchangeably in the remainder of the paper, because the distinction is not relevant for our model.

${ }^{6}$ For an assessment of the net benefits and the effectiveness of the HAMP program in particular, see Hembre (2014) and Scharlemann and Shore (2016).
} 


\section{RELATED LITERATURE}

We rely on the literature to motivate key assumptions in our model. Our first assumption is that homeowners have negative equity in their home, i.e., their mortgage balance exceeds the price of their house. When the borrower has positive equity in the property, it may not be optimal for them to default, especially if they can sell the property, pay off the mortgage, and keep or use the difference (Foote et al. $2008,2010)$. There is strong empirical evidence that borrower defaults happen in conjunction with negative equity (Deng et al. 2000; Danis and Pennington-Cross 2008; Gerardi et al. 2008; Campbell and Cocco 2015; Goodman et al. 2010; Ghent and Kudlyak 2011). The foreclosure crisis was characterized by falling house prices, which increased the number of borrowers with negative equity in their homes. Campbell et al. (2011) argue that foreclosures exacerbated the house price decline by negatively affecting the prices of neighboring houses, further increasing the number of borrowers faced with negative equity. However, negative equity alone does not always imply that the borrower should choose to default (Deng et al. 2000; Foote et al. 2008, 2010). We allow for this by making default costly - in principle, the negative impact on the borrower's credit history, potential relocation costs, and other monetary and non-monetary costs can deter even those borrowers with negative equity from defaulting. ${ }^{7}$ We allow the cost of default to vary across borrowers in our model. As will become clear in the model section, this leads to borrowers of three broad types: those who self-cure (i.e., become current on their loan without receiving modified terms), those who redefault (i.e., default again after receiving a mortgage modification), and those in between (i.e., those who default without modified terms but remain current after a modification).

The fact that lenders have to face borrowers of different types has been cited as a reason for lenders' reluctance to renegotiate mortgages (White 2009a, 2009b; Adelino et al. 2013; Ghent 2011). Since renegotiation does not guarantee that the borrower will not default again in the future, the lender would not want to renegotiate mortgage terms with borrowers who would subsequently redefault on the loan. If they did, the lender would not only incur the losses associated with foreclosure, but also lose additional funds associated with the cost of renegotiations. Conversely, the lender would also not want to renegotiate with borrowers who could self-cure, since the modified terms would lead to

\footnotetext{
${ }^{7}$ The literature suggests that default is the result of a "double trigger" - negative home equity in conjunction with an adverse shock affecting the borrower's ability to make payments (see, for example, Gerardi et al. 2013; Elul et al. 2010). Our simple model abstracts from such adverse shocks.
} 
a loss of revenue for the lender without any offsetting benefits. In the cost-benefit analysis of Ambrose and Capone (1996), when either the probability of self-cure or redefault is sufficiently high, it is no longer optimal for the lender to consider loan renegotiation as an option. In fact, recent empirical evidence shows that these two categories comprise a sizeable portion of the borrowers. ${ }^{8}$ Thus, as pointed out by Adelino et al. (2013), in the presence of uncertainty about borrower types, lenders could prefer to foreclose. The goal of our analysis is to assess whether and how incentive payments change this calculus.

We model the renegotiation between the homeowner and lender as a sequential move game, which is consistent with previous literature (Adelino et al. 2013; Wang et al. 2002). A key difference is that, while prior works highlight the role of information asymmetry as a barrier to successful renegotiations, we aim to uncover issues that might arise even with full information in the presence of incentives. ${ }^{9}$ Our contribution is thus to assess the effectiveness of incentives absent any other barriers to renegotiation. We also provide a simple theoretical underpinning for empirical observations about programs such as HAMP. For example, certain parameterization of our model can explain why lenders renegotiate only a small fraction of delinquent loans, as pointed out by Adelino et al. (2013). ${ }^{10}$ In the presence of incentives, our model predicts that the subset of homeowners who receive a modification and avoid foreclosure is larger. This is consistent with Agarwal et al. (2012) and Scharlemann and Shore (2016), who find that HAMP led to a modest reduction in foreclosures. Papers that focus on recent modification programs find that these programs attract homeowners who might otherwise self-cure (see, for example, Mayer et al. 2014), which is also a result that our model delivers. In addition, we characterize parameters of the model under which lenders renegotiate with homeowners who subsequently redefault.

\footnotetext{
${ }^{8}$ Adelino et al. (2013) look at the sample of mortgages from 2005-08 and find that more than 30 percent of seriously delinquent borrowers end up becoming current on their mortgages without receiving any mortgage modification. On the other hand, around 20 to 50 percent of the borrowers default after receiving loan modification.

${ }^{9}$ In the presence of information asymmetry, lenders can choose to incur screening costs to distinguish between borrower types. Wang et al. (2002) show that the optimal policy of the lender in this case is to either: 1) screen through enough applications so that borrowers who could self-cure are discouraged from seeking assistance, or 2) to randomly reject requests for mortgage modification, at a rate that depends on liquidation cost and magnitude of default, among other factors.

${ }^{10}$ Data on the HAMP program suggests that this might be the case for HAMP as well: as of February 2014, servicers had processed over 7.7 million applications but have approved less than one-third of them (Making Home Affordable Program 2010).
} 


\section{THE MODEL}

In the model of strategic interaction, the players are a single lender and a continuum of homeowners of type $\alpha$, where $\alpha$ is uniformly distributed on the interval $[0,1]$. Let $M$ denote the mortgage balance and $P$ the market price of the home. It is assumed that $M-P>0$, based on the literature that finds that negative equity is a trigger for default, e.g., Foote et al. (2008).

Figure 1 illustrates the payoffs of the possible outcomes of the interaction between the lender $(L)$ and an individual homeowner $(H)$. The homeowner moves first and decides whether to seek renegotiation (denoted by action $s$ ) or not seek renegotiation $(n s)$. If he does not seek renegotiation and does not default on his mortgage (denoted by action $n d$ ), there is no change to his present situation and his payoff is 0 . If he defaults (denoted by action $d$ ), he is foreclosed upon and his payoff is $M-P-\alpha D$. This is because he loses the house, whose market value is $P$, but no longer has to pay the mortgage $M$. For the homeowner of type $\alpha$, the cost of defaulting is $\alpha D$. This expression reflects the assumption that homeowners differ in their cost of mortgage default. If the homeowner does not seek renegotiation and does not default, the lender receives the mortgage amount $M$ as per the original contract. If he defaults and is foreclosed upon, the lender takes possession of the house. Her payoff is the market value $P$ of the house less the cost associated with foreclosing on it, $F$.

Once the homeowner decides to seek renegotiation, the lender has to decide whether or not to agree. If the lender does not agree to renegotiate $(n a)$, the homeowner's payoffs are the same as in the case where he chose not to seek renegotiation. Thus the payoff to the homeowner of seeking but not receiving a modification and then not defaulting is 0 , while the payoff from defaulting is $M-P-\alpha D$. There is no change to the lender's payoff either; she receives $M$ if the homeowner does not default and $P-F$ if he does.

If the lender agrees, denoted by action $a$, the modification leads to the homeowner being paid an amount $A$. If the homeowner does not default, his payoff is $A$. In this case, the lender receives $M-A$. If the homeowner receives $A$ and still defaults, his payoff is $M-P-\alpha D+$ $\rho A$. Since there is no time dimension in the model, $\rho \in(0,1)$ loosely captures what might occur during the modification process. Consider an example in which a homeowner receives a lower interest rate. We can think of the total amount $A$ as the difference between the original payments and the new, lower payments under the new interest rate over the full length of the loan term. However, if the homeowner defaults and is foreclosed upon after making a few of the new payments, he 
Figure 1 Homeowner and Lender Payoffs

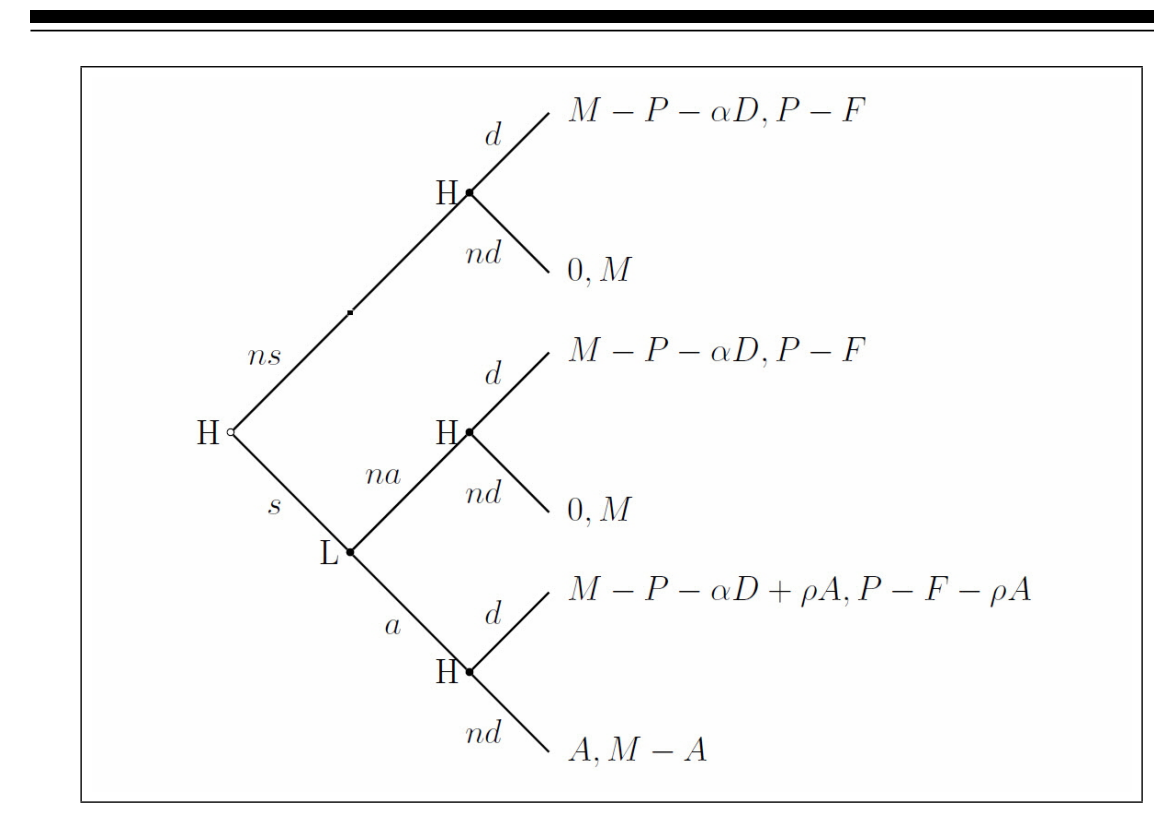

receives in effect only a fraction of the amount, i.e., $\rho A$. In this case, the lender's payoff is $P-F-\rho A$.

\section{Model with No Incentives}

We first assume that there is no government program in place. In other words, renegotiations between the lender and homeowner are purely bilateral with no externally funded incentives.

In principle, it is possible for the lender to choose both whether or not to renegotiate and how much to offer the homeowner. However, to avoid the complexities associated with a continuum of strategies, we assume for now that the lender has only two choices - not renegotiate (na) or agree to renegotiate and offer a specific amount $A=M-P{ }^{11}$ The payoffs under this specific assumption are shown in Figure 2.

In solving this game backward, we observe that homeowners can be grouped into types. Some homeowners would not default at any of

\footnotetext{
${ }^{11}$ This assumption follows Wang et al. (2002). Letting $A=M-P$ assumes in effect that the lender eliminates the homeowner's negative equity. Such a policy has actually been proposed and is critiqued in Gerardi and Willen (2009).
} 
the terminal nodes. For these homeowners, $\alpha \in[\bar{\alpha}, 1]$, where

$$
\bar{\alpha}=\frac{M-P}{D} .
$$

Also observe that there are homeowners who would get a higher payoff from defaulting even when offered $A$. For these homeowners, $\alpha \in[0, \underline{\alpha})$, where

$$
\underline{\alpha}=\frac{\rho(M-P)}{D} .
$$

We assume that $0<\underline{\alpha}<\bar{\alpha}<1$. In other words, homeowners can be grouped into three categories: (i) those with $\alpha \in[0, \underline{\alpha}$ ) who would default even if they received a modification, (ii) those with $\alpha \in[\bar{\alpha}, 1]$ who would not default even if they received no modification, and (iii) those with $\alpha \in[\underline{\alpha}, \bar{\alpha})$ who would default if they received no modification but not if they received a modification.

In the absence of any renegotiation between the lender and homeowners, all homeowners with $\alpha \in[0, \bar{\alpha})$ would default on their mortgages and be foreclosed upon while all homeowners with $\alpha \in[\bar{\alpha}, 1]$ would not. The lender's payoff in this case would be

$$
\bar{\alpha}(P-F)+(1-\bar{\alpha}) M .
$$

We now formally describe the solution to the model by characterizing the subgame perfect Nash equilibrium. This requires specifying the strategy profile that includes strategies of every player. Since there is a continuum of homeowners, we describe strategy profiles over intervals within $[0,1]$.

Proposition 1 Assume full information (the homeowners' type and the lenders' actions are observable). Let $\underline{\alpha}=\frac{\rho(M-P)}{D}$ and $\bar{\alpha}=\frac{M-P}{D}$. Then the strategy profile ${ }^{12}$

$$
\begin{array}{r}
\{(s \text { Always choose } d), n a\} \quad \forall \alpha \in[0, \underline{\alpha}) \\
\{(s \quad n d|A=M-P d| \text { otherwise }), a\} \forall \alpha \in[\underline{\alpha}, \bar{\alpha}) \\
\{(s \text { Always choose } n d), n a\} \forall \alpha \in[\bar{\alpha}, 1]
\end{array}
$$

is a subgame perfect Nash equilibrium of the game in Figure 2. ${ }^{13}$

Proof. See Appendix.

\footnotetext{
${ }^{12}$ The strategy profile is of the form $\{$ (Homeowner's strategy at initial node Homeowner's conditional strategy at terminal nodes), Lender's strategy $\}$.

${ }^{13}$ Note that the subgame perfect Nash equilibrium is not unique. To be specific, strategy profiles in which homeowners with $\alpha \in[0, \underline{\alpha})$ and $\alpha \in[\bar{\alpha}, 1]$ always chose action $n s$, or randomize between $s$ and $n s$, would also be subgame perfect Nash equilibria because the payoffs from the two are the same.
} 
Figure 2 Homeowner and Lender Payoffs with A=M-P

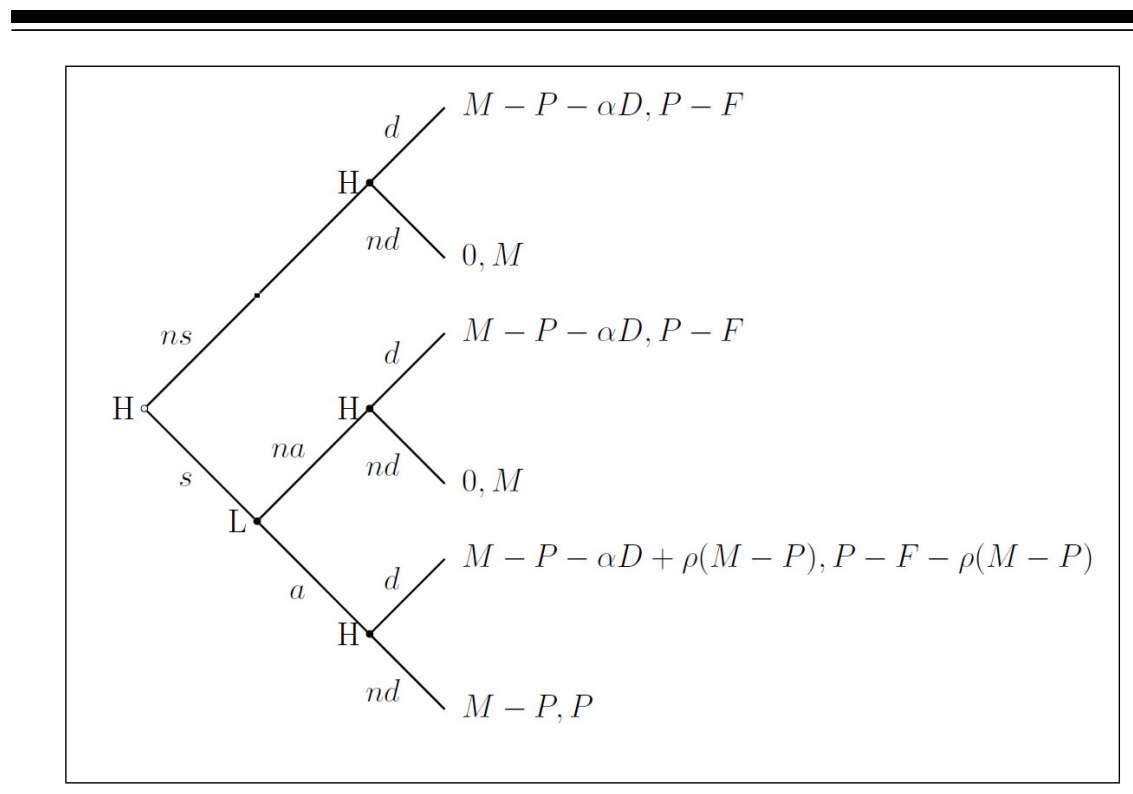

The preceding result shows that there is an equilibrium in which all types of homeowners choose to seek renegotiation. This illustrates the point that Adelino et al. (2013) make: renegotiation exposes the lender to homeowners who would self-cure (those with $\alpha \in[\bar{\alpha}, 1]$ in our model) or redefault (those with $\alpha \in[0, \underline{\alpha})$ ). The lender does not renegotiate with homeowners of type $\alpha \in[0, \underline{\alpha})$ because they would default even if they received a modification. As a result, the lender's payoff from renegotiating, $P-F-\rho A$, would be strictly less than her payoff from not doing so, $P-F$. The lender also does not renegotiate with homeowners of type $\alpha \in[\bar{\alpha}, 1]$ because her payoff from not modifying the terms, $M$, is strictly higher than her payoff from modifying the terms, $M-A$. In this equilibrium, the only homeowners whose mortgage terms are modified are of type $\alpha \in[\underline{\alpha}, \bar{\alpha})$. These are homeowners who would have gone through foreclosure in the absence of the modification but avoid foreclosure because they receive it.

It can be shown that the payoff to the lender from the above solution exceeds the payoff from the solution with no renegotiation as described by equation (3).

Certain parameterizations of the model can yield results consistent with empirical observations. For example, Adelino et al. (2013) point out that lenders renegotiate only a small fraction of delinquent loans. 


\section{Figure 3 Homeowner and Lender Payoffs with Incentives}

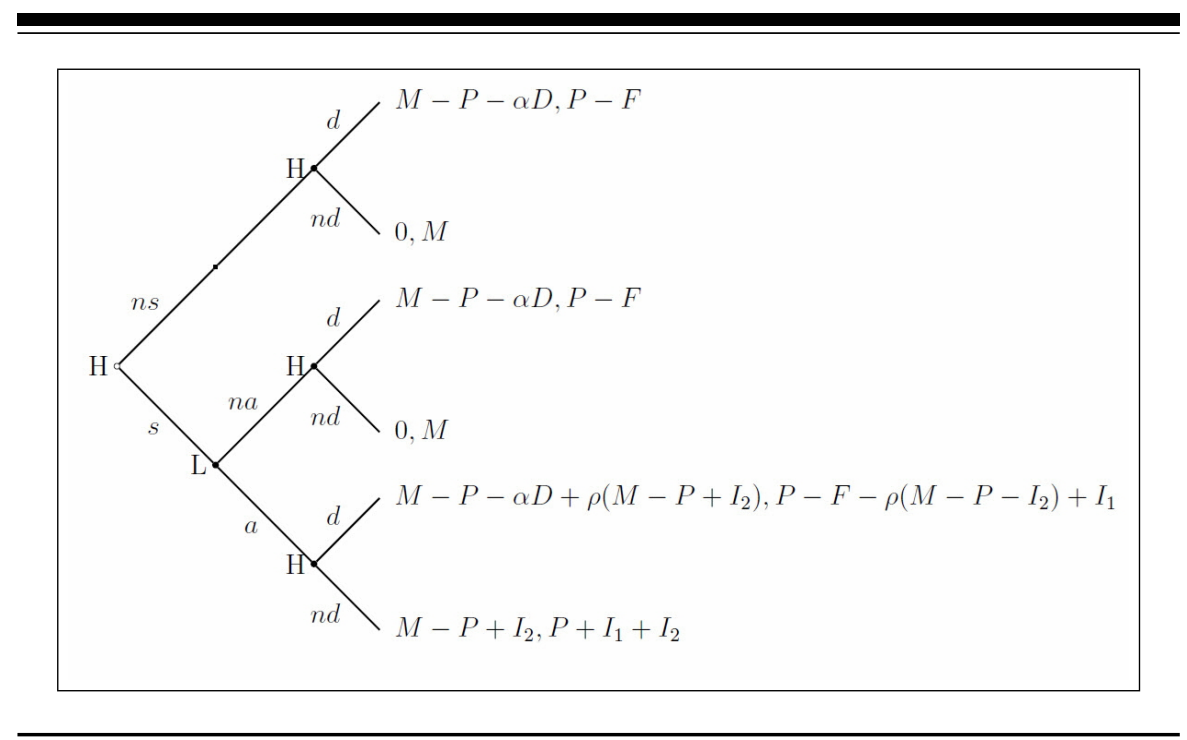

Our model can obtain a qualitatively similar result if the interval $[\underline{\alpha}, \bar{\alpha})$ is small, that is, if the number of homeowners who would successfully avoid foreclosure with a modification is small relative to the number who would redefault or self-cure.

\section{Model with Incentives}

We now solve the model in the presence of a government program that gives incentives to homeowners and lenders. We are particularly interested in comparing the solutions from this model to the model without the program to see whether the former is more effective in terms of preventing foreclosure.

The model of homeowner and lender renegotiation in the presence of incentives is shown in Figure 3. Our modeling of incentives is motivated by HAMP rules that were in place in 2010. Specifically, the program offered incentive compensation of $\$ 1,000$ to servicers for each permanent modification completed (Making Home Affordable Program 2010). In addition, it offered up to $\$ 1,000$ each to the homeowner and servicer for every year that the loan remained in good standing (or $\$ 83.33$ monthly), for a maximum of three years. We introduce this incentive compensation structure into our model as follows. The lender receives $I_{1}$ for offering a modification, regardless of whether or not the 
homeowner subsequently defaults. If the homeowner does not default and thereby avoids foreclosure, the lender receives an additional $I_{2}$ as "pay-for-success." As before, we use $\rho$ to capture what might happen during the modification period. In particular, if the homeowner remains current for a few periods after the renegotiation, both the homeowner and the lender would receive partial pay-for-success payments $\rho I_{2}$.

To compare the solution from this model to the model with no incentives, assume that all other variables are the same as before. We first show that an equilibrium exists in which a larger fraction of homeowners receives modifications and avoids foreclosure. The incentives thus have the effect of preventing some foreclosures that would have occurred in the absence of the program. The following result characterizes the equilibrium.

Proposition 2 Assume full information. Let $\underline{\alpha}^{\prime}=\frac{\rho(M-P)-(1-\rho) I_{2}}{D}$ and $\bar{\alpha}=\frac{M-P}{D}$. Assume that $\rho(M-P) \geq(1-\rho) I_{2}$, that $\rho\left(M-P-I_{2}\right)>$ $I_{1}$, and that $I_{1}+I_{2}<M-P$. Then the strategy profile

$$
\begin{aligned}
\{(s \text { Always choose } d), n a\} & \forall \alpha \in\left[0, \underline{\alpha}^{\prime}\right) \\
\{(s n d|A=M-P d| \text { otherwise }), a\} & \forall \alpha \in\left[\underline{\alpha}^{\prime}, \bar{\alpha}\right) \\
\{(s \text { Always choose } n d), n a\} & \forall \alpha \in[\bar{\alpha}, 1]
\end{aligned}
$$

is a subgame perfect Nash equilibrium of the game in Figure $3 .^{14}$

Proof. See Appendix.

Comparing Proposition 2 to Proposition 1, we see that the results are qualitatively similar. All homeowners seek renegotiation, but the lender offers it only to the subset of homeowners who can successfully avoid foreclosure as a result. The key difference is that the subset of homeowners who receive a modification and avoid foreclosure is larger in this case. This follows from the fact that $\underline{\alpha}^{\prime}<\underline{\alpha}$. Intuitively, the homeowners' payoff from receiving a modification and not defaulting is increased by the incentive payment $I_{2}$, which makes this option attractive to a larger fraction of homeowners.

The next result shows that, under different assumptions about the incentive structure, lenders may be induced to also renegotiate with homeowners of type $\alpha \in\left[0, \underline{\alpha}^{\prime}\right)$, and that these homeowners will subsequently default.

${ }^{14}$ For the same reasons as described for Proposition 1, the equilibrium is not unique. 
Proposition 3 Assume full information. Let $\underline{\alpha}^{\prime}=\frac{\rho(M-P)-(1-\rho) I_{2}}{D}$ and $\bar{\alpha}=\frac{M-P}{D}$. Assume that $\rho(M-P) \geq(1-\rho) I_{2}$, that $I_{1} \geq M-P-I_{2}$, and that $I_{1}+I_{2}<M-P$. Then the strategy profile

$$
\begin{aligned}
\{(s \text { Always choose } d), a\} & \forall \alpha \in\left[0, \underline{\alpha}^{\prime}\right) \\
\{(s \quad n d|A=M-P d| \text { otherwise }), a\} & \forall \alpha \in\left[\underline{\alpha}^{\prime}, \bar{\alpha}\right) \\
\{(n s \text { Always choose } n d), n a\} & \forall \alpha \in[\bar{\alpha}, 1]
\end{aligned}
$$

is a subgame perfect Nash equilibrium of the game in Figure 3.

Proof. See Appendix.

As in Proposition 2, a larger fraction of homeowners receives modifications and avoids foreclosure compared to the no-incentive case. The key difference between this result and Proposition 2 is that the lender now also renegotiates with all homeowners of type $\alpha \in[0, \bar{\alpha})$. Homeowners of this type subsequently default and are foreclosed upon. The reason for the difference in the two results is the incentive structure. In particular, the incentive payment given to the lender simply for renegotiating, $I_{1}$, is higher than in the previous case and also higher than the pay-for-success incentive $I_{2}$ (this follows from the assumptions in Proposition 3). This makes it worthwhile for the lender to renegotiate even with those homeowners who default. ${ }^{15}$

Proposition 3 highlights the fact that the parameters of the incentive structure can make the program less effective, in the sense of allocating some incentives to renegotiations that still result in foreclosure. This can happen, for example, if the pay-for-success payment, $I_{2}$, is not much higher than the incentive to participate, $I_{1}$, and if the homeowner redefaults fairly quickly, i.e., if $\rho$ is also low.

Finally, observe that it is possible in theory but unlikely in practice to have incentives large enough to induce lenders to renegotiate with homeowners who would otherwise self-cure. This can be seen if the proof of Proposition 2 was reworked under the assumption that $I_{1}+I_{2} \geq$ $M-P$. This is an unlikely assumption in practice because it requires that the incentive payments exceed the modification amount that the lender offers.

To summarize, our models show that in the absence of incentives, the lender renegotiates the mortgage terms of a subset of homeowners who avoid foreclosure as a result. In the presence of incentives, the lender renegotiates with a larger subset of homeowners who avoid foreclosure as a result. However, under certain assumptions about the

${ }^{15}$ Mayer et al. (2009) propose an incentive fee structure that would avoid this scenario by rewarding servicers only for successful modifications. 
incentive structure, the lender may also renegotiate with homeowners who subsequently default and are foreclosed upon.

\section{Mortgage Modifications and Success Rates}

Mortgage modifications are often evaluated by comparing "success rates" - defined as the fraction of homeowners who avoid foreclosure - across homeowners who do and do not receive modifications. Our models show that this comparison is not necessarily informative about the effectiveness of mortgage modifications. This is because success rates among those who do not receive modifications may be high if this group includes a large proportion of homeowners who self-cure. The solutions described by Proposition 1 and Proposition 2 illustrate this. In those solutions, the success rate conditional on not receiving a modification is $\frac{1-\bar{\alpha}}{1-\bar{\alpha}+\alpha}$. This number can be close to 1 if the interval $[\bar{\alpha}, 1]$ is large relative to the interval $[0, \underline{\alpha}]$. Recent research suggests that this is indeed the case. For example, Mayer et al. (2014) find that borrowers who became delinquent following a program announcement to help seriously delinquent borrowers were "those who appear to have been least likely to default otherwise." ${ }^{16}$ As a result, cure rates or success rates can end up being high among those who do apply but do not receive modifications. The conclusion is that success rate comparisons should be interpreted with caution when judging the effectiveness of mortgage modification programs.

\section{CONCLUSION}

The model in this paper provides a simple framework to analyze mortgage renegotiation between homeowner and lender. The results allow for a comparison of outcomes in the absence of incentives to outcomes in the presence of externally funded incentives to homeowners and lenders. In the absence of incentives, lenders renegotiate only with those homeowners who would successfully avoid foreclosure upon receiving a modification but would default without it. In other words, lenders do not renegotiate with homeowners who would self-cure without a modification or with homeowners who would default despite receiving it. The share of homeowners who receive modifications and avoid foreclosure is larger in the presence of incentives, and in some cases incentives might also induce lenders to renegotiate with homeowners who subsequently default. It is beyond the scope of this paper

\footnotetext{
${ }^{16}$ Andersson et al. (2013) also suggest that HAMP may have made default on mortgage debt more attractive.
} 
to determine whether the benefit exceeds the cost of providing such incentives or the overall impact of such programs on foreclosure prevention.

An important caveat is that this paper abstracts from information asymmetry between the lender and homeowner. We think that is a reasonable abstraction that enables us to focus on considerations even in the presence of full information. As Agarwal et al. (2012) describe, HAMP, for example, had extensive screening criteria, including trial periods, that likely enabled lenders to learn a lot about the homeowners. However, to the extent that asymmetric information is an issue, it may overstate how much lenders are able to target the "right" homeowners. Nonetheless, the point we illustrate is that even if lenders are able to target the right homeowners, externally funded incentives may lead them to also renegotiate with homeowners who cannot be protected from foreclosure.

\section{APPENDIX}

\section{Proof of Proposition 1}

Proof. We show that the strategy profile is a subgame perfect Nash equilibrium by solving the game in Figure 2 by backward induction.

For homeowners of type $\alpha \in[0, \underline{\alpha})$, we show that the payoff from action $d$ exceeds the payoff from action $n d$ at each of the three terminal nodes in Figure 2, working from top to bottom.

1. $M-P-\alpha D>0$ by assumption

2. $M-P-\alpha D>0$ by assumption

3. Given that the lender is offering $A=M-P$, the homeowner's payoff from choosing action $n d$ is $M-P$ and from $d$ is $M-P-$ $\alpha D+\rho(M-P)$. The homeowner will choose $d$ if and only if

$$
\begin{aligned}
& M-P-\alpha D+\rho(M-P)>M-P \\
& \text { that is } \Leftrightarrow \alpha<\frac{\rho(M-P)}{D},
\end{aligned}
$$

which is true because in this case $\alpha \in[0, \underline{\alpha})$ and $\underline{\alpha}=\frac{\rho(M-P)}{D}$.

Knowing that homeowners with $\alpha \in[0, \underline{\alpha})$ always choose action $d$, the lender will choose action $n a$ because her payoff from doing so, $P-F$, strictly exceeds her payoff from offering $a, P-F-\rho(M-P)$. 
By backward induction, knowing that the lender will choose $n a$, the homeowner will be indifferent between choosing $s$ and $n s$ at the initial node because the payoff is $M-P-\alpha D$ in each case.

For homeowners of type $\alpha \in[\underline{\alpha}, \bar{\alpha})$, we show that the payoff from action $d$ exceeds the payoff from action $n d$ at the top two terminal nodes and the payoff from $n d$ exceeds the payoff from $d$ at the bottom terminal node:

1. $M-P-\alpha D>0$ by assumption

2. $M-P-\alpha D>0$ by assumption

3. Given that the lender is offering $A=M-P$, the homeowner's payoff from choosing action $n d$ is $M-P$ and from $d$ is $M-P-$ $\alpha D+\rho(M-P)$. The homeowner will choose $d$ if and only if

$$
\begin{aligned}
M-P-\alpha D+\rho(M-P) & >M-P \\
& \Leftrightarrow \alpha<\frac{\rho(M-P)}{D},
\end{aligned}
$$

which is false because in this case $\alpha \in[\underline{\alpha}, \bar{\alpha})$ and $\underline{\alpha}=\frac{\rho(M-P)}{D}$.

Knowing that homeowners with $\alpha \in[\underline{\alpha}, \bar{\alpha})$ choose action $n d \mid A=$ $M-P$ and $d$ otherwise, the lender will choose action $a$ because her payoff from doing so, $P$, strictly exceeds her payoff from $n a, P-F$. By backward induction, knowing that the lender will choose $a$, the homeowner will choose $s$ at the initial node because $M-P>M-P-$ $\alpha D$.

For homeowners of type $\alpha \in[\bar{\alpha}, 1]$, we show that the payoff from action $n d$ exceeds the payoff from action $d$ at each terminal node in Figure 2, working from top to bottom.

1. $M-P-\alpha D<0$ by assumption

2. $M-P-\alpha D<0$ by assumption

3. Given that the lender is offering $A=M-P$, the homeowner's payoff from choosing action $n d$ is $M-P$ and from $d$ is $M-P-$ $\alpha D+\rho(M-P)$. The homeowner will choose $d$ if and only if

$$
\begin{aligned}
& M-P-\alpha D+\rho(M-P)>M-P \\
& \text { that is } \Leftrightarrow \alpha<\frac{\rho(M-P)}{D},
\end{aligned}
$$

which is false because in this case $\alpha \in[\bar{\alpha}, 1]$ and $\bar{\alpha}=\frac{(M-P)}{D}>$ $\frac{\rho(M-P)}{D}$. 
Knowing that homeowners with $\alpha \in[\bar{\alpha}, 1]$ always choose action $n d$, the lender will choose action $n a$ because her payoff from doing so, $M$, strictly exceeds her payoff from offering $a, P$. By backward induction, knowing that the lender will choose $n a$, the homeowner will be indifferent between choosing $s$ and $n s$ at the initial node because the payoff is 0 in each case.

\section{Proof of Proposition 2}

Proof. We show that the strategy profile is a subgame perfect Nash equilibrium by solving the game in Figure 3 by backward induction. The assumption that $\rho(M-P) \geq(1-\rho) I_{2}$ ensures that $\underline{\alpha}^{\prime} \in[0, \underline{\alpha})$.

For homeowners of type $\alpha \in\left[0, \underline{\alpha}^{\prime}\right)$, we show that the payoff from action $d$ exceeds the payoff from action $n d$ at each terminal node in Figure 3, working from top to bottom.

1. $M-P-\alpha D>0$ by assumption

2. $M-P-\alpha D>0$ by assumption

3. Given that the lender is offering $A=M-P$, the homeowner's payoff from choosing action $n d$ is $M-P+I_{2}$ and from $d$ is $M-P-\alpha D+\rho\left(M-P+I_{2}\right)$. The homeowner will choose $d$ if and only if

$$
\begin{aligned}
& M-P-\alpha D+\rho\left(M-P+I_{2}\right)>M-P+I_{2} \\
& \text { that is } \Leftrightarrow \alpha<\frac{\rho(M-P)-(1-\rho) I_{2}}{D},
\end{aligned}
$$

which is true because in this case $\alpha \in\left[0, \underline{\alpha}^{\prime}\right)$ and $\underline{\alpha}^{\prime}=$ $\frac{\rho(M-P)-(1-\rho) I_{2}}{D}$.

Knowing that homeowners with $\alpha \in\left[0, \underline{\alpha}^{\prime}\right)$ always choose action $d$, the lender will compare her payoff from $a$, which is $P-F-\rho(M-P-$ $\left.I_{2}\right)+I_{1}$, to her payoff from choosing action $n a$, which is $P-F$. The lender will choose $a$ if and only if

$$
\begin{aligned}
P-F-\rho\left(M-P-I_{2}\right)+I_{1} & \geq P-F \\
\text { that is, } & \Leftrightarrow I_{1} \geq \rho\left(M-P-I_{2}\right),
\end{aligned}
$$

which is false by assumption. Hence the lender will choose na. By backward induction, knowing that the lender will choose $n a$, the homeowner will be indifferent between choosing $s$ and $n s$ at the initial node because the payoff is $M-P-\alpha D$ in either case.

For homeowners of type $\alpha \in\left[\underline{\alpha}^{\prime}, \bar{\alpha}\right)$, we show that the payoff from action $d$ exceeds the payoff from action $n d$ at the top two terminal 
nodes and the payoff from $n d$ exceeds the payoff from $d$ at the bottom terminal node:

1. $M-P-\alpha D>0$ by assumption

2. $M-P-\alpha D>0$ by assumption

3. Given that the lender is offering $A=M-P$, the homeowner's payoff from choosing action $n d$ is $M-P+I_{2}$ and from $d$ is $M-P-\alpha D+\rho\left(M-P+I_{2}\right)$. The homeowner will choose $d$ if and only if

$$
\begin{aligned}
M-P-\alpha D+\rho\left(M-P+I_{2}\right) & >M-P+I_{2} \\
& \Leftrightarrow \alpha<\frac{\rho(M-P)-(1-\rho) I_{2}}{D},
\end{aligned}
$$

which is false because in this case $\alpha \in\left[\underline{\alpha}^{\prime}, \bar{\alpha}\right)$ and $\underline{\alpha}^{\prime}=$ $\frac{\rho(M-P)-(1-\rho) I_{2}}{D}$.

Knowing that homeowners with $\alpha \in\left[\underline{\alpha}^{\prime}, \bar{\alpha}\right)$ choose action $n d \mid A=$ $M-P$ and $d$ otherwise, the lender will choose action $a$ because her payoff from doing so, $P+I_{1}+I_{2}$, strictly exceeds her payoff from $n a$, $P-F$. By backward induction, knowing that the lender will choose $a$, the homeowner will choose $s$ at the initial node because $M-P+I_{2}>$ $M-P-\alpha D$.

For homeowners of type $\alpha \in[\bar{\alpha}, 1]$, we show that the payoff from action $n d$ exceeds the payoff from action $d$ at each terminal node in Figure 2, working from top to bottom.

1. $M-P-\alpha D<0$ by assumption

2. $M-P-\alpha D<0$ by assumption

3. Given that the lender is offering $A=M-P$, the homeowner's payoff from choosing action $n d$ is $M-P+I_{2}$ and from $d$ is $M-P-\alpha D+\rho\left(M-P+I_{2}\right)$. The homeowner will choose $d$ if and only if

$$
\begin{aligned}
& M-P-\alpha D+\rho\left(M-P+I_{2}\right)>M-P+I_{2} \\
& \text { that is } \Leftrightarrow \alpha<\frac{\rho(M-P)-(1-\rho) I_{2}}{D},
\end{aligned}
$$

which is false because in this case $\alpha \in[\bar{\alpha}, 1]$ and $\bar{\alpha}=\frac{(M-P)}{D}>$ $\frac{\rho(M-P)-(1-\rho) I_{2}}{D}$.

Knowing that homeowners with $\alpha \in[\bar{\alpha}, 1]$ always choose action $n d$, the lender will compare her payoff from $a$, which is $P+I_{1}+I_{2}$, to her 
payoff from choosing action $n a$ which is $M$. The lender will choose $a$ if and only if

$$
\begin{aligned}
P+I_{1}+I_{2} & \geq M, \\
\text { that is } & \Leftrightarrow I_{1}+I_{2} \geq M-P,
\end{aligned}
$$

which is false by assumption. Thus the lender will choose $n a$ in this case. By backward induction, knowing that the lender will choose na, the homeowner will be indifferent between choosing $s$ and $n s$ at the initial node because his payoff is 0 in either case.

\section{Proof of Proposition 3}

Proof. We show that the strategy profile is a subgame perfect Nash equilibrium by solving the game in Figure 3 by backward induction. The assumption that $\rho(M-P) \geq(1-\rho) I_{2}$ ensures that $\underline{\alpha}^{\prime} \in[0, \underline{\alpha})$.

For homeowners of type $\alpha \in\left[0, \underline{\alpha}^{\prime}\right)$, we show that the payoff from action $d$ exceeds the payoff from action $n d$ at each terminal node in Figure 3, working from top to bottom.

1. $M-P-\alpha D>0$ by assumption

2. $M-P-\alpha D>0$ by assumption

3. Given that the lender is offering $A=M-P$, the homeowner's payoff from choosing action $n d$ is $M-P+I_{2}$ and from $d$ is $M-P-\alpha D+\rho\left(M-P+I_{2}\right)$. The homeowner will choose $d$ if and only if

$$
\begin{aligned}
& M-P-\alpha D+\rho\left(M-P+I_{2}\right)>M-P+I_{2} \\
& \text { that is } \Leftrightarrow \alpha<\frac{\rho(M-P)-(1-\rho) I_{2}}{D},
\end{aligned}
$$

which is true because in this case $\alpha \in\left[0, \underline{\alpha}^{\prime}\right)$ and $\underline{\alpha}^{\prime}=$ $\frac{\rho(M-P)-(1-\rho) I_{2}}{D}$.

Knowing that homeowners with $\alpha \in\left[0, \underline{\alpha}^{\prime}\right)$ always choose action $d$, the lender will compare her payoff from $a$, which is $P-F-\rho(M-P-$ $\left.I_{2}\right)+I_{1}$, to her payoff from choosing action $n a$, which is $P-F$. The lender will choose $a$ if and only if

$$
\begin{aligned}
& P-F-\rho\left(M-P-I_{2}\right)+I_{1} \geq P-F \\
& \text { that is, } \Leftrightarrow I_{1} \geq \rho\left(M-P-I_{2}\right),
\end{aligned}
$$

which is true by assumption. Hence the lender will choose $a$. By backward induction, knowing that the lender will choose $a$, the homeowner 
will compare choosing $n s$ with choosing $s$. He will choose the latter if and only if

$$
M-P-\alpha D+\rho\left(M-P+I_{2}\right) \geq M-P-\alpha D,
$$

which is true. Hence the homeowner will indeed choose $s$.

For homeowners of type $\alpha \in\left[\underline{\alpha}^{\prime}, \bar{\alpha}\right)$, we show that the payoff from action $d$ exceeds the payoff from action $n d$ at the top two terminal nodes and the payoff from $n d$ exceeds the payoff from $d$ at the bottom terminal node:

1. $M-P-\alpha D>0$ by assumption

2. $M-P-\alpha D>0$ by assumption

3. Given that the lender is offering $A=M-P$, the homeowner's payoff from choosing action $n d$ is $M-P+I_{2}$ and from $d$ is $M-P-\alpha D+\rho\left(M-P+I_{2}\right)$. The homeowner will choose $d$ if and only if

$$
\begin{aligned}
M-P-\alpha D+\rho\left(M-P+I_{2}\right) & >M-P+I_{2} \\
& \Leftrightarrow \alpha<\frac{\rho(M-P)-(1-\rho) I_{2}}{D},
\end{aligned}
$$

which is false because in this case $\alpha \in\left[\underline{\alpha}^{\prime}, \bar{\alpha}\right)$ and $\underline{\alpha}^{\prime}=$ $\frac{\rho(M-P)-(1-\rho) I_{2}}{D}$.

Knowing that homeowners with $\alpha \in\left[\underline{\alpha}^{\prime}, \bar{\alpha}\right)$ choose action $n d \mid A=$ $M-P$ and $d$ otherwise, the lender will choose action $a$ because her payoff from doing so, $P+I_{1}+I_{2}$, strictly exceeds her payoff from $n a$, $P-F$. By backward induction, knowing that the lender will choose $a$, the homeowner will choose $s$ at the initial node because $M-P+I_{2}>$ $M-P-\alpha D$.

For homeowners of type $\alpha \in[\bar{\alpha}, 1]$, we show that the payoff from action $n d$ exceeds the payoff from action $d$ at each terminal node in Figure 3, working from top to bottom.

1. $M-P-\alpha D<0$ by assumption

2. $M-P-\alpha D<0$ by assumption

3. Given that the lender is offering $A=M-P$, the homeowner's payoff from choosing action $n d$ is $M-P+I_{2}$ and from $d$ is $M-P-\alpha D+\rho\left(M-P+I_{2}\right)$. The homeowner will choose $d$ if and only if

$$
\begin{aligned}
& M-P-\alpha D+\rho\left(M-P+I_{2}\right)>M-P+I_{2} \\
& \text { that is } \Leftrightarrow \alpha<\frac{\rho(M-P)-(1-\rho) I_{2}}{D},
\end{aligned}
$$


which is false because in this case $\alpha \in[\bar{\alpha}, 1]$ and $\bar{\alpha}=\frac{(M-P)}{D}>$ $\frac{\rho(M-P)-(1-\rho) I_{2}}{D}$.

Knowing that homeowners with $\alpha \in[0, \underline{\alpha})$ always choose action $n d$, the lender will compare her payoff from $a$, which is $P+I_{1}+I_{2}$, to her payoff from choosing action $n a$, which is $M$. The lender will choose $a$ if and only if

$$
\begin{aligned}
P+I_{1}+I_{2} & \geq M \\
\text { that is } & \Leftrightarrow I_{1}+I_{2} \geq M-P,
\end{aligned}
$$

which is false by assumption. Thus the lender will choose $n a$ in this case. By backward induction, knowing that the lender will choose na, the homeowner will be indifferent between choosing $s$ and $n s$ at the initial node because the payoff from either action is 0 . 


\section{REFERENCES}

Adelino, Manuel, Kristopher Gerardi, and Paul S. Willen. 2013. "Why Don't Lenders Renegotiate More Home Mortgages? Redefaults, Self-cures, and Securitization." Journal of Monetary Economics 60 (October): 835-53.

Agarwal, Sumit, Gene Amromin, Itzhak Ben-David, Souphala Chomsisengphet, Thomasz Piskorski, and Amit Seru. 2012. "Policy Intervention in Debt Renegotiation: Evidence from the Home Affordable Modification Program." Working Paper 18311. Cambridge, Mass.: National Bureau of Economic Research. (August).

Ambrose, Brent W., and Charles A. Capone Jr.. 1996. "Cost-Benefit Analysis of Single-Family Foreclosure Alternatives." Journal of Real Estate Finance and Economics 13 (September): 105-20.

Andersson, Fredrik, Souphala Chomsisengphet, Dennis Glennon, and Feng Li. 2013. "The Changing Pecking Order of Consumer Defaults." Journal of Money, Credit and Banking 45 (March/April): 251-75.

Campbell, John Y., and João F. Cocco. 2015. "A Model of Mortgage Default." Journal of Finance 70 (August): 1495-554.

Campbell, John Y., Stefano Giglio, and Parag Pathak. 2011. "Forced Sales and House Prices." American Economic Review 101 (August): 2108-31.

Danis, Michelle A., and Anthony Pennington-Cross. 2008. "The Delinquency of Subprime Mortgages." Journal of Economics and Business 60 (January/February): 67-90.

Deng, Yongheng, John M. Quigley, and Robert Van Order. 2000. "Mortgage Terminations, Heterogeneity and the Exercise of Mortgage Options." Econometrica 68 (March): 275-307.

Elul, Ronel, Nicholas S. Souleles, Souphala Chomsisengphet, Dennis Glennon, and Robert Hunt. 2010. "What 'Triggers' Mortgage Default?" American Economic Review 100 (May): 490-4.

Foote, Christopher L., Kristopher Gerardi, Lorenz Goette, and Paul S. Willen. 2010. "Reducing Foreclosures: No Easy Answers." In NBER Macroeconomics Annual, vol. 24, ed. Daron Acemoglu, Kenneth Rogoff, and Michael Woodford. Chicago: University of Chicago Press, 89-138 
Foote, Christopher L., Kristopher Gerardi, and Paul S. Willen. 2008. "Negative Equity and Foreclosure: Theory and Evidence." Journal of Urban Economics 64 (September): 234-45.

Gerardi, Kristopher, Kyle F. Herkenhoff, Lee E. Ohanian, and Paul S. Willen. 2013. "Unemployment, Negative Equity and Strategic Default." Federal Reserve Bank of Atlanta Working Paper 2013-4 (August).

Gerardi, Kristopher and Wenli Li. 2010. "Mortgage Foreclosure Prevention Efforts." Federal Reserve Bank of Atlanta Economic Review 95 (October): 1-13.

Gerardi, Kristopher, Adam Hale Shapiro, and Paul S. Willen. 2008. "Subprime Outcomes: Risky Mortgages, Homeownership Experiences, and Foreclosures." Federal Reserve Bank of Boston Working Paper 07-15 (May).

Gerardi, Kristopher, and Paul S. Willen. 2009. "Subprime Mortgages, Foreclosures, and Urban Neighborhoods." BE Journal of Economic Analysis 8 Policy 9 (March): 1-37.

Ghent, Andra C. June 2011. "Securitization and Mortgage Renegotiation: Evidence from the Great Depression." Review of Financial Studies 24 (June): 1814-47.

Ghent, Andra C., and Marianna Kudlyak. 2011. "Recourse and Residential Mortgage Default: Evidence from US States." Review of Financial Studies 24 (September): 3139-86.

Goodman, Laurie S., Roger Ashworth, Brian Landy, and Ke Yin. 2010. "Negative Equity Trumps Unemployment in Predicting Defaults." Journal of Fixed Income 19 (Spring): 67-72.

Hembre, Erik. 2014. "HAMP, Home Attachment, and Mortgage Default." Working Paper (February).

Making Home Affordable Program. 2010. "Making Home Affordable Program Handbook for Servicers of Non-GSE Mortgages Version 2.0." https://www.hmpadmin.com/portal/programs/docs/hamp_ servicer/mhahandbook_20.pdf [August 10, 2015].

Mayer, Christopher, Edward Morrison, and Thomasz Piskorski. 2009. "A New Proposal for Loan Modifications." Yale Journal on Regulation 26 (Summer): 417-29

Mayer, Christopher, Edward Morrison, Thomasz Piskorski, and Arpit Gupta. 2014. "Mortgage Modification and Strategic Behavior:

Evidence from a Legal Settlement with Countrywide." American Economic Review 104 (September): 2830-57. 
Neelakantan, Urvi, Kimberly Zeuli, Shannon McKay, and Nika Lazaryan. 2012. "Staring Down Foreclosure: Findings from a Sample of Homeowners Seeking Assistance." Manuscript, Federal Reserve Bank of Richmond.

RealtyTrac Staff. 2014. "1.4 Million U.S. Properties with Foreclosure Filings in 2013 Down 26 Percent to Lowest Annual Total Since 2007." RealtyTrac.com (January 13).

Scharlemann, Therese C., and Stephen H. Shore. 2016. "The Effect of Negative Equity on Mortgage Default: Evidence from HAMP's Principal Reduction Alternative." Review of Financial Studies 29 (October): 2850-83.

U.S. Department of the Treasury. 2014. "HAMP Application Activity by Servicer, as of February 28, 2014." http://www.treasury.gov/initiatives/financialstability/reports/Pages/HAMP-Servicer.aspx [August 10, 2015].

Wang, Ko, Leslie Young, and Yuqing Zhou. 2002. "Nondiscriminating Foreclosure and Voluntary Liquidating Costs." Review of Financial Studies 15 (April): 959-85.

White, Alan M. 2009a. "Deleveraging the American Homeowner: The Failure of 2008 Voluntary Mortgage Contract Modifications." Connecticut Law Review 41 (May): 1107-31.

White, Alan M. 2009b. "Rewriting Contracts, Wholesale: Data on Voluntary Mortgage Modifications from 2007 and 2008 Remittance Reports." Fordham Urban Law Journal 36: 509-35. 